\title{
Mutation of RGA1, which encodes a putative GTPase-activating protein for the polarity-establishment protein Cdc42p, activates the pheromone-response pathway in the yeast Saccharomyces cerevisiae
}

\author{
Brian J. Stevenson, ${ }^{1,2,4}$ Betsy Ferguson, ${ }^{1}$ Claudio De Virgilio, ${ }^{3}$ Erfei Bi, ${ }^{3}$ John R. Pringle, ${ }^{3}$ \\ Gustav Ammerer, ${ }^{2}$ and George F. Sprague Jr. ${ }^{1,5}$ \\ ${ }^{1}$ Department of Biology and Institute of Molecular Biology, University of Oregon, Eugene, Oregon 97403 USA; ${ }^{2}$ Department \\ of Biochemistry and Molecular Cell Biology, University of Vienna, A-1030 Vienna, Austria; ${ }^{3}$ Department of Biology, \\ University of North Carolina, Chapel Hill, North Carolina 27599 USA
}

\begin{abstract}
We have selected yeast mutants that exhibit a constitutively active pheromone-response pathway in the absence of the $\beta$ subunit of the trimeric $G$ protein. Genetic analysis of one such mutant revealed that it contained recessive mutations in two distinct genes, both of which contributed to the constitutive phenotype. One mutation identifies the RGA1 locus (Rho GTPase activating protein), which encodes a protein with homology to GAP domains and to LIM domains. Deletion of RGA1 is sufficient to activate the pathway in strains lacking the GB subunit. Moreover, in wild-type strains, deletion of RGA1 increases signaling in the pheromone pathway, whereas over-expression of RGA1 dampens signaling, demonstrating that Rga1p functions as a negative regulator of the pheromone response pathway. The second mutation present in the original mutant proved to be an allele of a known gene, PBS2, which encodes a putative protein kinase that functions in the high osmolarity stress pathway. The pbs2 mutation enhanced the rga1 mutant phenotype, but by itself did not activate the pheromone pathway. Genetic and two-hybrid analyses indicate that an important target of Rga1p is Cdc42p, a p21 GTPase required for polarity establishment and bud emergence. This finding coupled with recent experiments with mammalian and yeast cells indicating that Cdc42p can interact with and activate Ste20p, a protein kinase that operates in the pheromone pathway, leads us to suggest that Rga1p controls the activity of Cdc42p, which in turn controls the magnitude of signaling in the pheromone pathway via Ste20p.
\end{abstract}

[Key Words: RGA1; GAPs; Saccharomyces cerevisiae; pheromone-response pathway; Cdc42p]

Received September 1, 1995; revised version accepted October 19, 1995.

Mating between the haploid cell types of Saccharomyces cerevisiae is controlled by the reciprocal exchange of extracellular peptide pheromones. Binding of pheromone to specific cell-surface receptors activates an intracellular pathway that leads to transcriptional induction of genes required for the mating process and to arrest of the mitotic cell cycle in the $G_{1}$ phase (for review, see Marsh et al. 1991; Sprague and Thorner 1992; Kurjan 1993). The current view of the pathway, based both on genetic

\footnotetext{
4 Present address: Sandoz Pharma Ltd. CH-4002 Basel, Switzerland. ${ }^{5}$ Corresponding author.
}

epistasis analysis and on biochemical reconstitution of a segment of the pathway, is summarized below.

Pheromone binds to cell type-specific receptors at the cell surface-a-factor binds to Ste3p on $\alpha$ cells and $\alpha$-factor binds to Ste2p on a cells. These receptors belong to the seven transmembrane family and transduce their signal through a trimeric $G$ protein common to both cell types. Binding of ligand to receptor causes the $G \alpha$ subunit, Gpalp, to dissociate from the G $\beta \gamma$ dimer, Ste $4 p-$ Ste 18p, which then activates a downstream component of the pathway. The identity of this G $\beta \gamma$ target molecule(s) remains unknown. Subsequent signal transmission, however, depends on the protein kinase Ste20p (Leberer et al. 1992; Ramer and Davis 1993) and on a 
three-tiered MAP kinase module composed of Ste11p, Ste $7 p$, and the partially redundant MAP kinases Fus $3 p$ and Kss1p (Cairns et al. 1992; Gartner et al. 1992; Stevenson et al. 1992; Errede et al. 1993; Zhou et al. 1993; Neiman and Herskowitz 1994). Another pathway component, Ste5p, is required for efficient signal transmission, in part at least because it appears to organize the MAP kinase module into a complex (Choi et al. 1994; Kranz et al. 1994; Marcus et al. 1994; Printen and Sprague 1994). The targets of the MAP kinases include Ste12p, a transcription factor that mediates induction of pheromone-responsive genes (Dolan and Fields 1989; Errede and Ammerer 1989), and Farlp, a protein that mediates cell-cycle arrest (Chang and Herskowitz 1990; Peter et al. 1993; Tyers and Futcher 1993). Ste12p appears to be a substrate for both Fus3p and Ksslp (Elion et al. 1993), whereas Farlp is a substrate only for Fus3p (Elion et al. 1993; Peter et al. 1993; Tyers and Futcher 1993). Thus, these studies imply that the pheromone response pathway components function in the order: receptor $\rightarrow$ G protein $\rightarrow$ Ste20p $\rightarrow$ Stellp $\rightarrow$ Ste $7 p \rightarrow$ Fus $3 p, K s s l p \rightarrow$ Ste12p and Farlp. At odds with this strictly linear arrangement, however, are recent findings that suggest that Ste20p activity is modulated by several inputs, or has several output targets. In particular, Ste20p is partially redundant with Cla4p, a related protein kinase; the double mutant cannot maintain septin rings at the bud neck and cannot undergo cytokinesis (Cvrcková et al. 1995).

Most of the pathway components described above were identified by an identical genetic strategy-the isolation of mutants (or strains carrying genes on multicopy plasmids) that were nonresponsive to pheromone. Because the connection between the $G$ protein and the MAP kinase module is poorly understood and because components or regulators encoded by essential or redundant genes might have been missed by application of that strategy, we elected to isolate constitutive mutants in which pathway signaling occurs autonomously of a receptor-ligand interaction (Stevenson et al. 1992; J. Shultz, A. Rogat, and G.F. Sprague, Jr., unpubl.|. Here we present the analysis of one such mutant, which identifies the $R G A 1$ (Rho GTPase activating protein) gene. The $R G A 1$ product $\bar{h}$ as homology to GTPase activating proteins (GAPs) for p21 GTPases of the Rho subfamily. We present two-hybrid and genetic data that $\mathrm{Cdc} 42 \mathrm{p}$, a protein known to be required for polarity establishment and bud emergence, is an important target of Rgalp. Loss of Rgalp function activates the pheromone response pathway in ste $4 \Delta(\mathrm{G} \beta)$ mutants, but not in ste11 1 mutants, implying that Rgalp serves as a negative regulator of the pathway at a step between the $G$ protein and the MAP kinase module. These findings, together with the recent findings that a mammalian homolog of Cdc $42 p$ activates a homolog of Ste20p (Manser et al. 1994), that yeast Cdc42p and Ste20p interact (Simon et al. 1995; Zhao et al. 1995), and that Cdc42p is required for pheromone response (Simon et al. 1995; Zhao et al. 1995), imply that the activity of Cdc $42 p$ is an important modulator of signaling in the pheromone response pathway.

\section{Results}

rgal-1 activates the pheromone signal transduction pathway

To isolate mutants in which signal transmission through the pheromone-response pathway is activated or enhanced independent of a receptor-ligand interaction, we used a ste $4 \Delta$ his 3 mutant strain carrying a chromosomal FUS1::HIS3 construct (Stevenson et al. 1992). In this strain, the basal pathway signal normally seen in wildtype cells is absent. As a result, the FUS1 promoter is inactive (Hagen et al. 1991; also see Table 1) and the cells have a His ${ }^{-}$phenotype. We selected mutants that could grow on medium lacking histidine and containing $3 \mathrm{~mm}$ amino triazole (AT), a competitive inhibitor of the His3p enzyme (Stevenson et al. 1992). This condition requires that pathway activity be restored to basal level or higher. The His ${ }^{+}$phenotype of mutant 27 was recessive (Stevenson et al. 1992), implying that it identified a negative regulator of the pheromone pathway. This mutant was chosen for further study.

Genetic analysis of mutant 27 revealed that it contained two recessive, independently segregating mutations (see Materials and methods). One mutation, subsequently designated rga1-1 (see below), activated the FUS1 promoter as evidenced by the $\mathrm{His}^{+}$phenotype of a ste $4 \Delta$ his3 FUS1::HIS3 strain. The effect of the rga1-1 mutation was quantitated by monitoring the expression of a FUS1-lacZ reporter gene. As shown in Table 1, rga1-1 restored pathway signaling to the basal level seen in wild-type cells (compare strains BSY179, 187, and 191). The second mutation (later identified as an allele of PBS2 and dubbed pbs2-99| did not activate FUS1::HIS3 on its own, but enhanced the phenotype conferred by rga1-1 (Table 1). Indeed, together the rga1-1 and pbs2-99 mutations restored some mating competence to ste $4 \Delta$ strains, but neither mutation alone did (Table 1 and data not shown). The second mutation ( $p b s 2-99$ ) conferred an additional phenotype, sensitivity to osmotic stress, providing a clue to its identity.

\section{RGAl encodes a large protein with homology to LIM domains and to Rho GAP domains}

As a first step in the molecular characterization of the two genes identified by mutant 27 , it was transformed with a YEp24-based yeast genomic library (Carlson and Botstein 1982), and colonies were isolated that exhibited reduced expression of FUS1::HIS3 (see Materials and methods). Five clones were identified. Two of the five clones, which contained overlapping DNA inserts as determined by restriction-enzyme mapping, also complemented the osmotic-sensitivity phenotype of the original strain. We reasoned that these clones harbored the PBS2 gene on the basis of the following observations: The cloned DNA complemented and was linked genetically to the mutation that conferred sensitivity to osmotic stress; the cloned DNA mapped to chromosome $\mathrm{X}$, where others have mapped PBS2 (Boguslawski and Polazzi 1987); and the restriction-enzyme map and par- 
Table 1. FUS1-lacZ expression and mating capacity of rgal ste strains

\begin{tabular}{|c|c|c|c|}
\hline Strain & Genotype $^{a}$ & FUS1-lacZ expression ${ }^{\mathrm{b}}$ & Mating efficiency ${ }^{\mathfrak{c}}$ \\
\hline BSY179 & $R G A 1$ PBS2 & 5.3 & 0.9 \\
\hline BSY183 & rga1-1 PBS2 & 11.5 & 0.9 \\
\hline BSY185 & rga1-1 pbs2-99 & 20.2 & 1.0 \\
\hline BSY187 & ste $4 \Delta:: L E U 2$ RGA1 PBS2 & 0.3 & $<3 \times 10^{-8}$ \\
\hline BSY191 & ste $4 \Delta:: L E U 2$ rga1-1 PBS2 & 5.4 & $<3 \times 10^{-8}$ \\
\hline BSY193 & ste4A::LEU2 rga1-1 pbs2-99 & 17.0 & $5.5 \times 10^{-5}$ \\
\hline BSY231 & ste20A::URA3 RGA1 PBS2 & 0.4 & $5.3 \times 10^{-2}$ \\
\hline BSY233 & ste204::URA3 rga1-1 PBS2 & 2.1 & $3.6 \times 10^{-2}$ \\
\hline BSY235 & ste20A::URA3 rga1-1 pbs2-99 & 6.1 & 0.1 \\
\hline BSY219 & ste $5 \Delta:: U R A 3$ RGA1 PBS2 & 0.3 & $<5 \times 10^{-8}$ \\
\hline BSY221 & ste $5 \Delta:: U R A 3$ rga1-1 PBS2 & 7.6 & $<4 \times 10^{-8}$ \\
\hline BSY223 & ste $5 \Delta:: U R A 3$ rga1-1 pbs2-99 & 20.5 & $7.0 \times 10^{-5}$ \\
\hline BSY225 & ste11A::URA3 RGA1 PBS2 & 0.3 & $<3 \times 10^{-8}$ \\
\hline BSY227 & ste11A::URA3 rga1-1 PBS2 & 0.3 & $<4 \times 10^{-8}$ \\
\hline BSY229 & ste11A::URA3 rga1-1 pbs2-99 & 0.3 & $<.3 \times 10^{-8}$ \\
\hline
\end{tabular}

${ }^{a}$ All strains also have the markers of SY2002.

${ }^{b} \beta$-Galactosidase activity was determined as described in Materials and methods. The reported values are the averages of at least three determinations.

${ }^{\mathrm{c}}$ Absolute mating efficiencies were determined as described in Materials and methods.

tial DNA sequence of the cloned DNAs matched that published for PBS2 (data not shown; Boguslawski and Polazzi 1987; see Materials and methods). PBS2 encodes a protein kinase thought to occupy the middle tier of a MAP-kinase module that functions in the high osmolarity stress (HOG) pathway.

The remaining three clones contained overlapping DNA inserts that complemented the $\mathrm{His}^{+}$phenotype of the original strain (conferred by the rga1-1 mutation) but not the osmotic sensitivity. The smallest of the cloned inserts (pRGA1.3) is shown in Figure 1. To ensure that this cloned DNA represented the RGA1 locus, and not

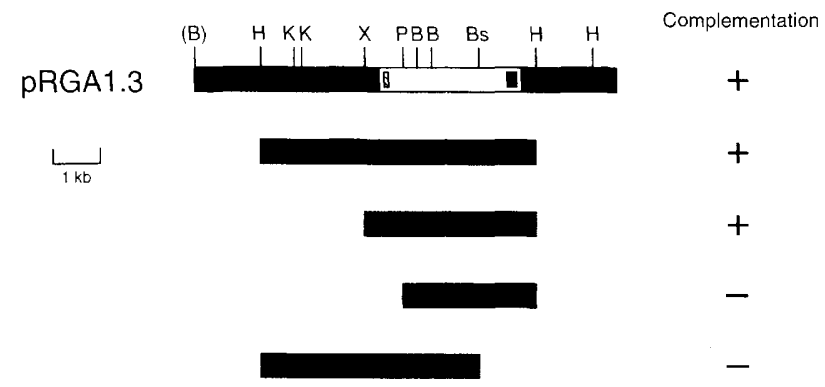

Figure 1. Restriction enzyme map of the RGA1 locus and location of the rga1-complementing activity. The $8.9-\mathrm{kb}$ genomic insert carried by the pRGAl.3 plasmid is shown as a gray rectangle. The open region corresponds to the RGA1 open reading frame, and the hatched and solid boxes within the open reading frame represent the LIM domains and the GAP homology region, respectively. Restriction enzyme sites shown are: (B) BamHI; (Bs) BstXI; (H) HindIII; (K) KpnI; (P) PstI; (X) XhoI. The ability of deletion derivatives of the insert to complement the $\mathrm{His}^{+}$phenotype in strain SY1731 (rga1-1 pbs2-99) is shown to the right. an unlinked high-copy suppressor, we performed genetic linkage analysis (see Materials and methods). The cloned DNA showed linkage to the rga1-1 mutation indicating that it indeed represented the RGA1 locus. Hybridization of a radiolabeled $0.3-\mathrm{kb}$ BamHI fragment (see Fig. 1) to a blot of intact chromosomes and to blots of an ordered array of lambda clones (Riles et al. 1993) revealed that RGA1 is located on the right arm of chromosome $\mathrm{XV}$ (data not shown).

The RGA1 gene was localized within pRGA1.3 by testing the ability of fragments of the clone to complement mutant 27 (Fig. 1). This analysis indicated that the minimal complementing sequence was a $3.6-\mathrm{kb}$ XhoIHindIII fragment (Fig. 1). The DNA sequence of the 4.1kb ClaI-HindIII fragment, shown in Figure 2, contains one long open reading frame capable of encoding a protein of 1007 amino acids. Rgalp has a predicted molecular weight of 112,802 daltons, and is likely to be an intracellular protein, because it contains no obvious signal sequence for secretion nor any putative transmembrane segments. The complement of nucleotides 3306 through 3328 of this sequence (double underline in Fig. 2) encode the last six residues and the translation stop of the Ade 2 protein, indicating that $R G A 1$ and $A D E 2$ are convergently transcribed, and confirming the assignment of RGA1 to the right arm of chromosome XV.

A homology search of the current GenBank data base by use of the BLAST algorithm (Altschul et al. 1990) identified two nonoverlapping segments of Rgalp that show significant similarity to previously identified proteins. Residues 13 through 66 in the amino-terminal region of Rgalp match the consensus of a LIM domain, and a second sequence (residues 70-122) is an imperfect match, with a conserved histidine replaced by a cysteine 


\section{Stevenson et al.}

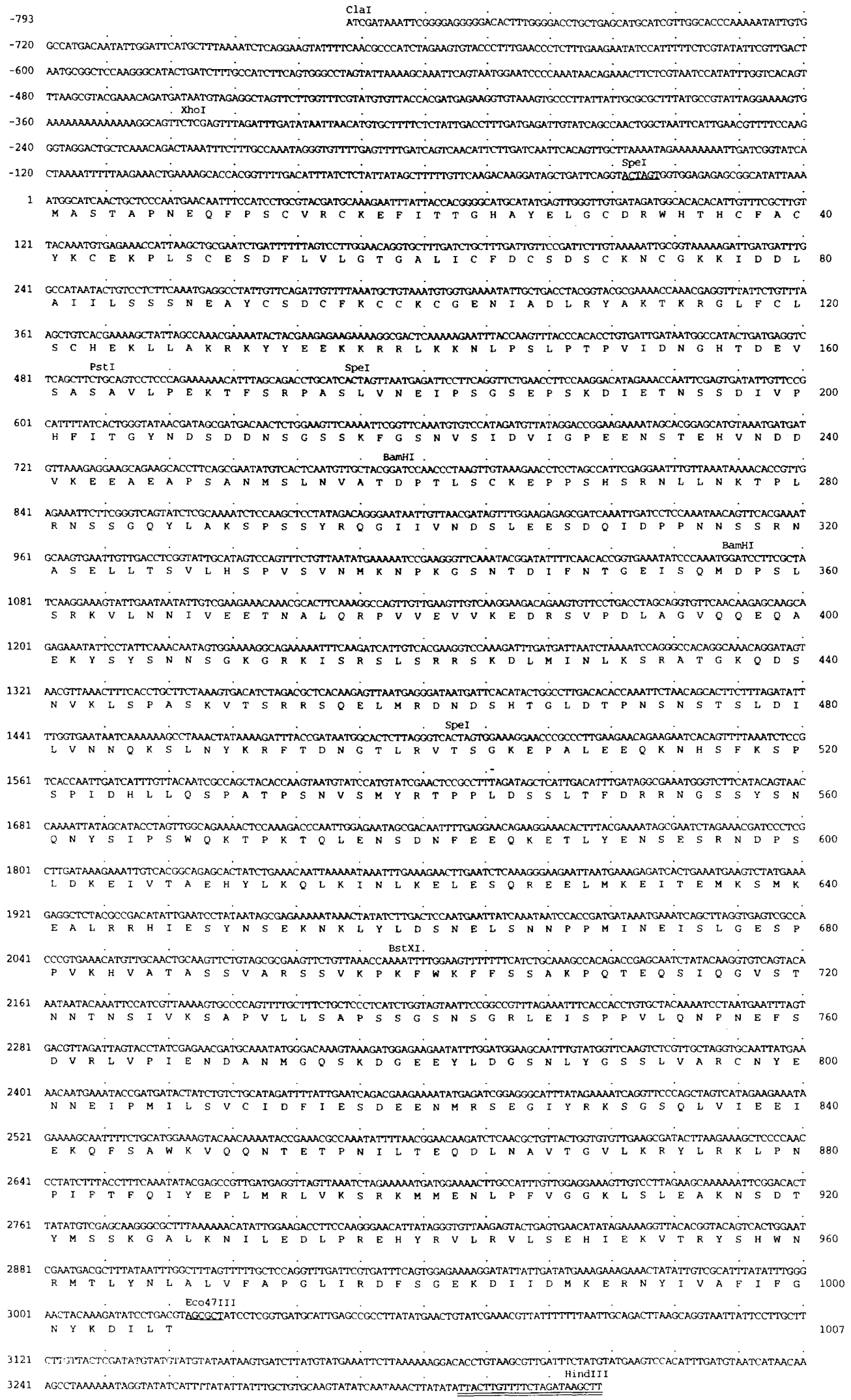

Figure 2. Sequence of the RGA1 gene. The DNA sequence of the 4.1-kb ClaI-HindIII fragment is shown, numbered to the left, with the predicted amino-acid sequence of Rgalp below, numbered to the right. The SpeI and Eco47III restriction enzyme sites used to construct rga1 $\triangle:: L E U 2$ are underlined. The complement of the DNA sequence coding for the last 6 residues of Ade2p is double underlined. 


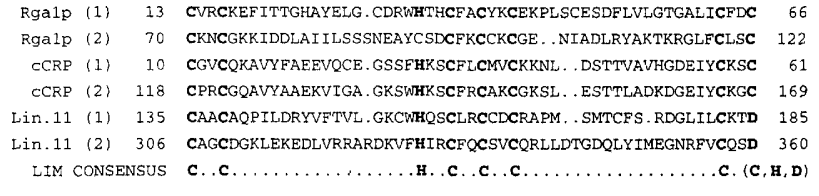

Figure 3. Rgalp contains two sequences with homology to LIM domains. The LIM domains of Lin-11 (Freyd et al. 1990) and cCRP (Crawford et al. 1994) are shown together with the homologous sequences from Rgalp. 1 and 2 refer to the position of the domains with respect to the amino terminus of the protein. The consensus sequence of the residues involved in zinc coordination are shown in boldface letters. Note that the imperfect Rgalp (2) sequence contains a cysteine in place of the conserved histidine.

(Fig. 3). LIM domains bind zinc ions (Michelsen et al. 1993; Archer et al. 1994) and are thought to mediate protein-protein interactions. They were first characterized in the homeo domain-containing proteins Lin-11, Isl-1, and Mec-3 (Way and Chalfie 1988; Freyd et al. 1990; Karlsson et al. 1990|, but have since been found in proteins that lack homeo domains, such as the chicken cysteine-rich protein (cCRP; Crawford et al. 1994).

The carboxy-terminal 200 residues of Rgalp show high similarity to sequences common to GTPase-activating proteins (GAPs), particularly to GAPs of the Rho subclass, which includes Rho, Rac, and Cdc42-like proteins (Fig. 4). GAPs enhance the low intrinsic GTPase activity of p21 GTP-binding proteins and consequently promote their inactivation. Several other GAPs have been identified in S. cerevisiae. Bud2p, Bem2p, and Bem3p, have functions required for bud morphogenesis or bud-site positioning (Park et al. 1993; Zheng et al. 1993, 1994; Peterson et al. 1994). Ira1p and Ira2p function as GAPs for Raslp and Ras2p (Tanaka et al. 1990). An additional GAP, Lrglp, has an unknown function, but is expressed at highest levels in sporulating cells (Müller et al. 1994).

Surprisingly, the data base search found an exact match between residues $570-639$ of Rgalp and a par- tially sequenced gene, THE1 (Ramer et al. 1992). Galactose-mediated overexpression of an amino-terminal truncation of THE1 leads to cell death in all cell types of S. cerevisiae. Assuming that RGA1 is identical to THE1, the cause of the lethality is likely to be overexpression of the GAP region of Rgalp. We tested this directly by constructing an allele of $R G A 1$ lacking the amino-terminal 537 amino acids, under control of the GAL1 promoter. Wild-type cells containing this construct grew well on glucose-containing medium but did not grow on medium containing galactose as the sole carbon source /data not shown), confirming that overexpression of the GAP domain of $R G A 1$ leads to growth arrest. C. Chan (pers. comm.) has also identified $R G A 1$ in an independent genetic screen as a suppressor of bem2 mutations.

\section{RGA1 is a nonessential gene}

The phenotype(s) of a null mutation of $R G A 1$ were examined by constructing a $M A T \mathbf{a} / M A T \alpha$ diploid strain heterozygous for a deletion that removes all of the RGA1 open reading frame $\{$ rga1 $:: L E U 2$, see Materials and methods). Sporulation of this strain (BSY237) gave rise to four viable spores per tetrad, indicating that $R G A 1$ is not an essential gene. We assayed FUS1-lacZ expression and mating efficiency in strains that contained rga1 $\triangle:: L E U 2$, alone or in combination with a pbs2 $2:: U R A 3$ allele, in a wild-type or ste $4 \Delta$ background. As shown in Table 2, deletion of RGA1 increased the expression of FUS1 in wild-type and ste $4 \Delta$ strains. In the absence of a functional G protein (ste $4 \Delta$ strains), only the rga1 $\Delta:: L E U 2$ pbs2A::URA3 double mutant showed some mating ability. These results are similar to those obtained with rga1-1 (Table 1), suggesting that rga1-1 is a loss-of-function allele, consistent with its recessiveness.

Many genes that affect the functioning of the pheromone signal-transduction pathway are selectively expressed in the haploid cell types or are inducible by pheromone (Sprague and Thorner 1992). To investigate the expression of RGA1, the centrally located $0.3-\mathrm{kb}$ BamHI

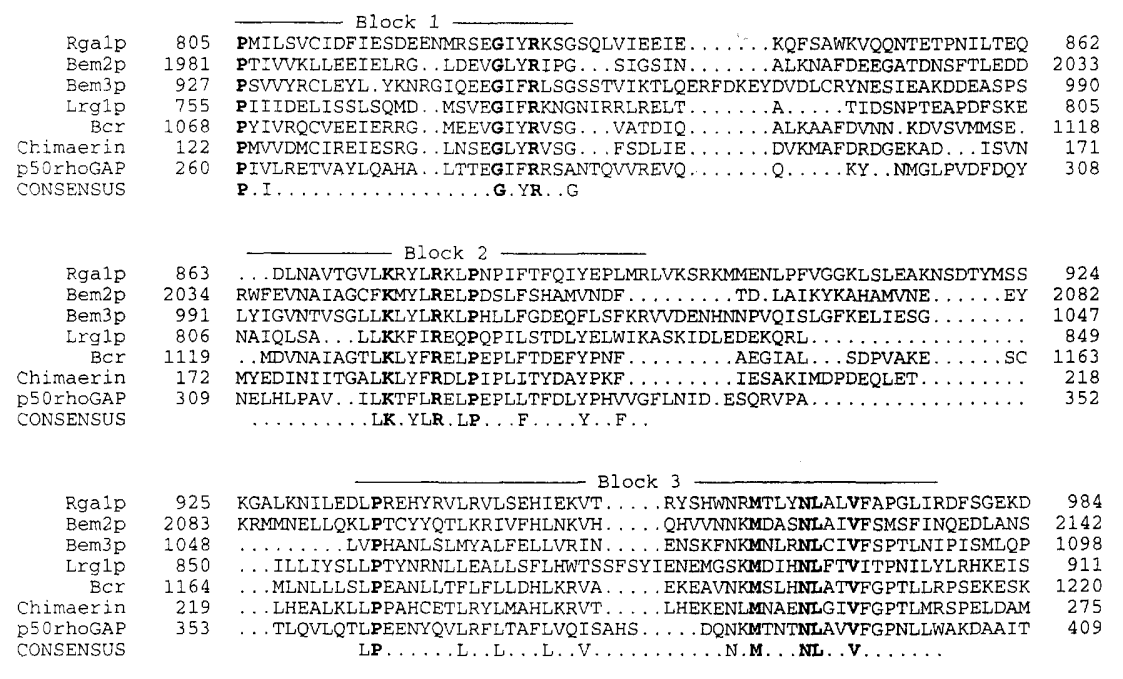

Figure 4. Rgalp has homology to Rho-GAP proteins. An alignment of the carboxy-terminal region of Rgalp with the Rho-GAP domains of six other proteins is presented, derived by use of the pileup program of the UWGCG package (Devereux et al. 1984). A consensus sequence, with invariant residues in bold, is shown for the highly conserved subdomains (Blocks 1-3; Zheng et al. 1993). The proteins are: $S$. cerevisiae Bem $2 p$ (Zheng et al. 1994); S. cerevisiae Bem3p (Peterson et al. 1994); S. cerevisiae Lrglp (Müller et al. 1994); human breakpoint cluster region (Bcr) protein (Heisterkamp et al. 1985); human n-chimaerin (Hall et al. 1990); and p50rhoGAP (Barfod et al. 1993; Lancaster et al. 1994). 
Table 2. Pheromone-response pathway activity in rga1 $1 \Delta:$ LEU2 and GAL-RGA1 strains

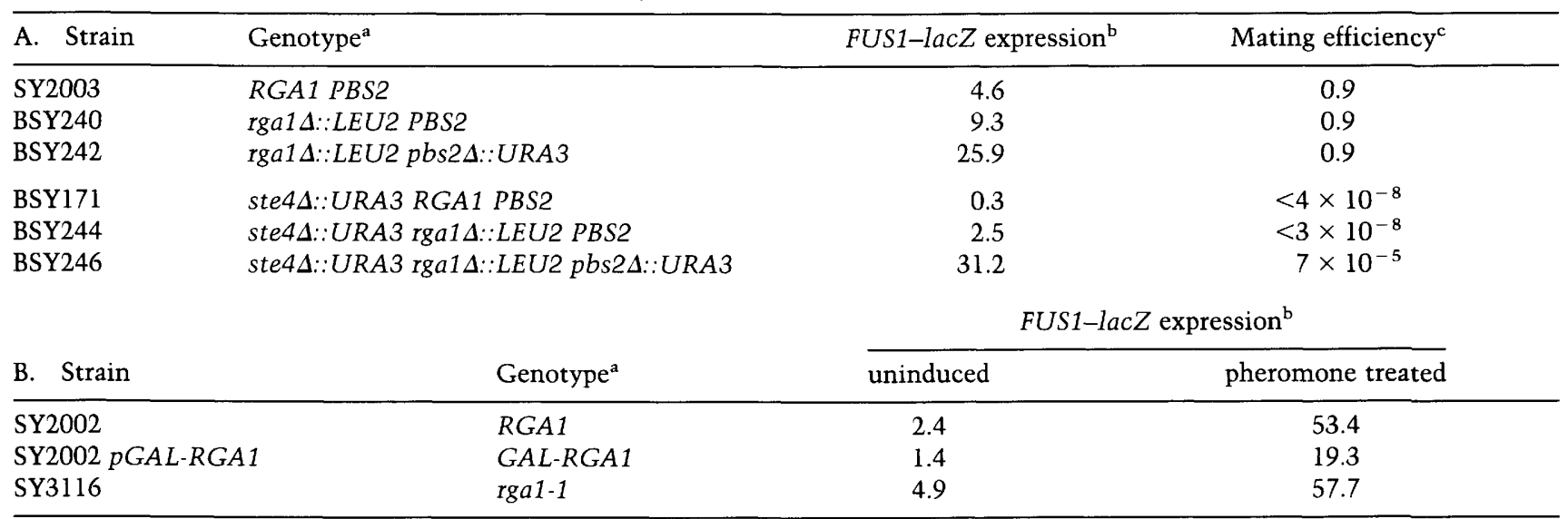

${ }^{a}$ All strains are isogenic to SY2002 except as indicated.

${ }^{\mathrm{b}} \beta$-Galactosidase activity was determined as described in Materials and methods, except for strains in $B$, which were grown in YEP-GAL medium. The reported values are the averages of at least three determinations.

${ }^{\mathrm{c}}$ Absolute mating efficiencies were determined as described in Materials and methods.

fragment was radiolabeled and used for Northern analysis. The $R G A 1$ probe hybridized with a $3.3-\mathrm{kb}$ RNA that was expressed in all cell types and was not inducible by pheromone (data not shown).

Although RGA1 is not an essential gene, loss of Rgalp activity causes a distinct change in cell morphology. Cells carrying the rga1-1 or rga1 $\Delta:: L E U 2$ allele appear elongated and display at most a few bud scars, usually at both poles of the cell (Fig. 5). Wild-type haploid cells typically display a chain of bud scars centered at one cell pole (Fig. 5; Chant and Herskowitz 1991; Chant and Pringle 1995). Pedigree analysis confirmed that rga1-1 mutants produce buds in a bipolar manner, whereas wild-type cells generated buds in the expected axial pattern. Although a bipolar bud-site selection pattern is typical of a/ $\alpha$ cells, rga1-1 mutants are otherwise phenotypically a or $\alpha$; they mate with cells of the opposite mating type, and the resulting diploids produce viable spores.

\section{Overexpression of RGAl reduces both basal pathway activity and response to pheromone}

We next tested the effect of overexpression of $R G A 1$ on signaling in the pheromone-response pathway. A singlecopy plasmid containing $R G A 1$ under the control of the GAL1 promoter was introduced into a wild-type strain, and pheromone pathway activity was monitored by use of the FUS1-lacZ reporter gene. When grown in the presence of $0.4 \mathrm{M}$ galactose, cells containing the GAL1$R G A 1$ gene produced about $50 \%$ less $\beta$-galactosidase activity than cells lacking the GAL1-RGA1 gene (Table 2). Similarly, in the presence of pheromone, the GAL1RGA1 cells produced $65 \%$ less $\beta$-galactosidase activity than cells with wild-type levels of Rgalp. These results are consistent with the hypothesis that Rgalp negatively regulates the pheromone-response pathway: Increased Rgalp reduces signaling through the pathway, whereas loss of Rgalp increases signaling.

\section{Rga1p functions at or before Ste11p} in the pheromone pathway

To determine at which point rga1-1 activates the pheromone-response pathway, we performed double-mutant analysis with known components of the pathway. Strains carrying deletions of STE5, STE11, STE7, STE12, or STE20 were crossed to a strain carrying both rga1-1 and pbs2-99, and segregants with ste deletions and
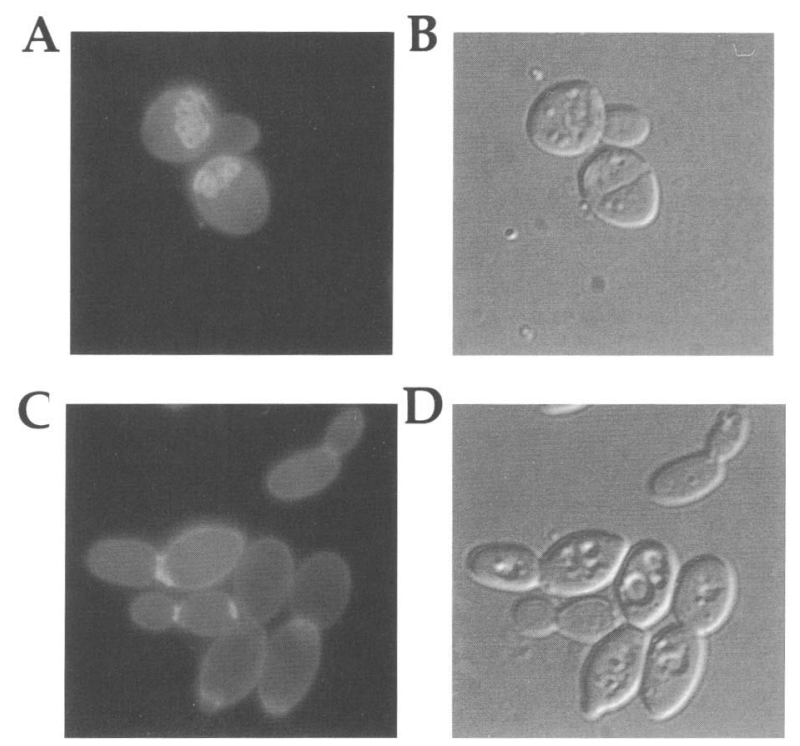

Figure 5. Bud-scar staining and cellular morphologies of RGA1 and rga1-1 strains. BSY187 and BSY191 were grown to exponential phase and stained with Calcofluor to illuminate bud scars as described in Materials and methods. RGA1 cells viewed with fluorescence $(A)$ or Nomarski optics $(B)$; rga1-1 cells viewed by fluorescence $(C)$ or Nomarski optics $(D)$. 
rga1-1 were assayed for FUS-1-1acZ expression. As expected, otherwise wild-type strains containing ste deletions expressed FUS1 at very low levels and showed no detectable mating activity. [We note that in contrast to published reports (Leberer et al. 1992; Ramer and Davis 1993), deletion of STE2O in our genetic background severely reduced the basal level of FUS1 expression but decreased the mating efficiency only about 10-fold below that of the $S T E^{+}$strain (Table 1). The reason for these differences is not known.] Activation of FUS1-lacZ expression by rga1-1 was apparent in ste $5 \Delta$ strains, and to a lesser extent in ste20 $\Delta$ strains. In contrast, rga1-1 had no effect in ste $11 \Delta$ strains (Table 1) or in ste $7 \Delta$ or ste $12 \Delta$ backgrounds (data not shown). The pbs2-99 allele enhanced the activity of rga1-1 by two- to threefold in ste $5 \Delta$ and ste20 $\Delta$ strains, and allowed ste $5 \Delta$ rga1-1 cells to mate, albeit at a low level (Table 1). These results suggest that rga1-1 exerts its effect before or at the same level as STE11 in the pathway.

\section{Rga1p exhibits genetic and two-hybrid interactions with $C d c 42 p$}

The sequence of RGA1 suggests that it encodes a GAP for a member of the p21 GTPase superfamily, most likely a Rho protein. We used the two-hybrid technique (Fields and Song 1989; Gyuris et al. 1993) to investigate the possibility that Rgalp interacts with known Rho/ Ras proteins, specifically Rholp, Rho2p, Rho3p, Rho4p, Rsrlp (Budlp), or Cdc42p. Interaction was detected between a Rgal activation-domain (AD) fusion protein and LexA-Cdc42p (Table 3A). The interaction with Cdc42p was substantially enhanced by introducing a C188S sub- stitution, which prevents prenylation, and a G12V or Q61L substitution, which should trap Cdc42p in the GTP-bound form. Conversely, a D118A substitution, which should lock Cdc42p out of the GTP-bound form, dramatically reduced interaction with Rgalp. Bem $3 p$, a protein with demonstrable GAP activity on Cdc42p in vitro (Zheng et al. 1994), also interacted with Cdc42p, although in this case, significant interaction was observed only with Cdc42p containing the Q61L and C188S substitutions. Because the LexA-Cdc42p fusions showed some ability to activate the lexAop-lacZ reporter on their own, we re-examined the interactions using LexA-Rgalp and -Bem $3 p$ fusion proteins in conjunction with $\mathrm{Cdc} 42 \mathrm{p}-\mathrm{AD}$ fusions. Interaction was again detected and was again stronger when $\mathrm{Cdc} 42 \mathrm{p}$ contained the C188S and G12V or Q61L substitutions (Table 3B); indeed, for Bem $3 p$, interaction was detected only for Cdc42p $\mathrm{p}^{\mathrm{Q} 61 \mathrm{~L}, \mathrm{C1885}}$. Rgalp-AD also interacted weakly with LexA-Rsrlp and -Rholp fusions (Table 3A), although in the former case, the G12V substitution apparently weakened the interactions. The Rho4p fusion interacted strongly with a RhoGDI (data not shown), indicating that the failure of this protein to interact with Rgalp and Bem $3 p$ is not simply because the RHO4 construct was faulty.

In a separate experiment, the ability of Rgalp to interact with components of the pheromone-response pathway was tested. No interactions were detected between Rgalp and Ste20p, Ste5p, Stel1p, Ste7p, or Fus3p (data not shown).

If Rgalp interacts with and serves as a GAP for $\mathrm{Cdc} 42 \mathrm{p}$, as the data above suggest, we reasoned that one should observe genetic interactions between RGA1 and

Table 3. Two-hybrid interactions between Rga1p and Rho/Ras proteins

\begin{tabular}{|c|c|c|c|}
\hline A. & pJG4-5-RGA1 & pJG4-5-BEM3 & pJG4-5 \\
\hline pEG202-CDC42 & 16 & 3 & 2 \\
\hline pEG202-CDC42 & 191 & 12 & 40 \\
\hline $\mathrm{pEG} 202-C D C 42^{G 12 V, C 188 S}$ & 4777 & 108 & 323 \\
\hline $\mathrm{pEG} 202-C D C 42^{\mathrm{Q} 61 L, C 188 S}$ & 3956 & 1798 & 311 \\
\hline pEG202-CDC42 & 12 & 37 & 6 \\
\hline pEG202-RHO1 & 84 & 20 & 7 \\
\hline pEG202-RHO1 & 14 & 17 & 30 \\
\hline pEG2O2-RHO2 & 6 & 14 & 20 \\
\hline pEG202-RHO2 ${ }^{\mathrm{C} 188 S, \mathrm{C} 189 \mathrm{~S}}$ & 10 & 26 & 26 \\
\hline pEG2O2-RHO3 & 4 & 27 & 6 \\
\hline pEG202-RHO3 ${ }^{\mathrm{C} 228 \mathrm{~S}}$ & 1 & 18 & 10 \\
\hline pEG202-RHO4 & 8 & 15 & 7 \\
\hline pEG2O2-RHO4 ${ }^{\mathrm{C} 288 \mathrm{~S}}$ & 26 & 20 & 69 \\
\hline pEG202-RSR1 & 189 & 13 & 5 \\
\hline pEG $202-R S R 1^{G 12 V}$ & 121 & N.D. & 4 \\
\hline pEG202-RAS2 & 9 & 15 & 4 \\
\hline B. & pEG202-RGA1 & pEG202-BEM3 & pEG202 \\
\hline pJG4-5-CDC42 & 2 & 3 & 20 \\
\hline pJG4-5-CDC42 & 26 & 1 & 18 \\
\hline pJG4-5-CDC42G12V.C188S & 561 & 4 & 26 \\
\hline pIG4-5-CDC42 Q61L,C188S & 2016 & 268 & 18 \\
\hline pJG4-5 & 5 & 5 & 17 \\
\hline
\end{tabular}


CDC42 and between RGA1 and genes encoding known regulators of $C d c 42 \mathrm{p}$. We first examined the effect of overexpression of $R G A 1$ on a $c d c 42^{t s}$ mutant, reasoning that an increase in Cdc42p GAP activity should reduce the amount of active Cdc $42 p$ and therefore lower the maximum temperature at which the mutant can grow. Indeed, expression of $R G A 1$ or $B E M 3$ from multicopy plasmids lowered the restrictive temperature of the $c d c 42^{t s}$ mutant (Fig. 6A). Even at room temperature, the presence of high-copy RGA1 or BEM3 caused a significant increase in the proportion of large round, unbudded cells, the terminal phenotype exhibited by cdc42-1 mutants (data not shown). We also examined the phenotype of a double-mutant strain containing mutations in $R G A 1$ and $C D C 24$, which encodes an essential GDP release factor (GRF) that stimulates the exchange of GTP for GDP on Cdc42p (Zheng et al. 1994). Deletion of $R G A 1$ raised the restrictive temperature of $c d c 24^{t s} \mathrm{mu}$ tants (Fig. 6B) and restored wild-type cell morphology at $30^{\circ} \mathrm{C}$ (Fig. 7, top row). In addition, the multi-copy suppression of $c d c 24^{t s}$ by $C D C 42$ (Bender and Pringle 1989) was abolished if either RGA1 or BEM3 was also present on a high-copy plasmid (Pringle et al. 1995). These findings support the hypothesis that Rgalp and Bem3p have a function opposite to that of $\mathrm{Cdc} 24 \mathrm{p}$; that is, they serve as GAPs, or negative regulators, of $\mathrm{Cdc} 42 \mathrm{p}$.

If both Rgalp and Bem3p serve as GAPs for Cdc42p, an rga1 bem 3 double mutant should have a more extreme phenotype than either single mutant. Indeed, in contrast to the single mutants, the rga1 $\Delta$ bem $3 \Delta$ double mutant had an aberrant, elongated cell morphology (Fig. 7, bottom row). The rga1 bem 3 mutant, however, was viable, even at elevated temperatures (Fig. $6 \mathrm{C}$ ), suggesting that there may also be additional GAPs that regulate Cdc42p.

Possible cross talk between the high osmolarity-stress pathway and the pheromone-response pathway

The ability of a pbs2 mutation to potentiate pheromonepathway signaling in an rgal mutant background was surprising because previous reports suggested that inactivation of $P B S 2$ had no effect on the mating pathway (Boguslawski 1992). To determine whether the ability of pbs2 to potentiate pheromone-pathway activity was specific for rga1, we performed two experiments. First, we tested the ability of pbs2-99 to enhance FUS1-lacZ expression in ste $4 \Delta$ strains containing weakly constitutive alleles of STE7 (Yashar et al. 1995). FUS1-lacZ expression was fourfold higher in the pbs2-99 strain than in the PBS2 strain (data not shown). Second, we stimulated the osmotic stress pathway by the addition of $1 \mathrm{M}$ sorbitol to the growth medium. This condition increased expression of FUS1-lacZ by 10 -fold in ste $4 \Delta$ pbs $2 \Delta$ cells but not in ste $4 \triangle P B S 2$ cells (Table 4; data not shown). Thus,
Figure 6. Genetic interactions among RGA1, BEM3, CDC42, and CDC24. Cells were grown on SD-Leu or YEPD medium at $23,30,35$, or $37^{\circ} \mathrm{C}$ for $24-36 \mathrm{hr}$. (A) Strain DITD2-16D (cdc42-1) with plasmids YEp13, YEp13-RGA1, and YEp13-BEM3 (B) Segregants from diploid SY3043, with relevant genotypes $c d c 24^{t s}$, rga1 $\triangle:: U R A 3$, and $c d c 24^{t s}$ rga1 $\triangle:$ URA3. (C) Segregants from diploid SY3032 with relevant genotypes rga1 $4:$ : $U R A 3$, bem $3 \Delta:: L E U 2$, and rga1A::URA3 bem3A::LEU2.

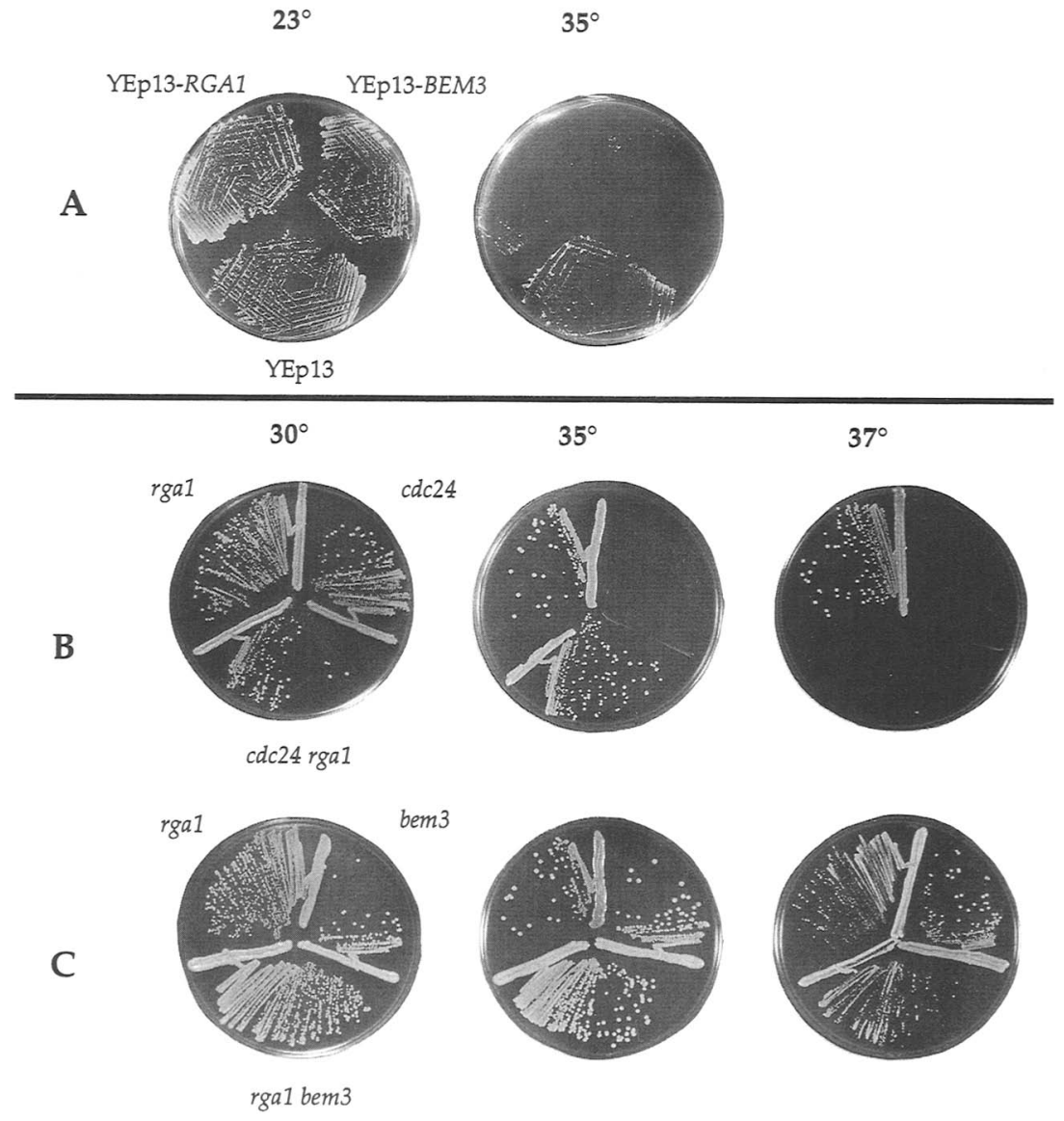




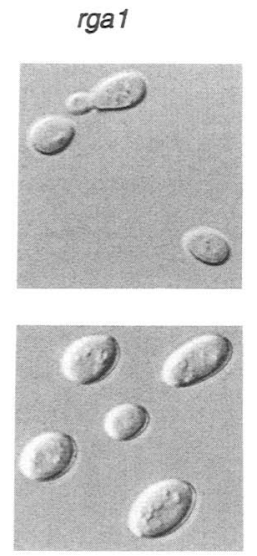

rga1
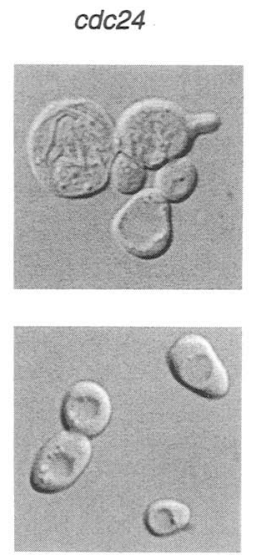

bem3 rga1 codc24
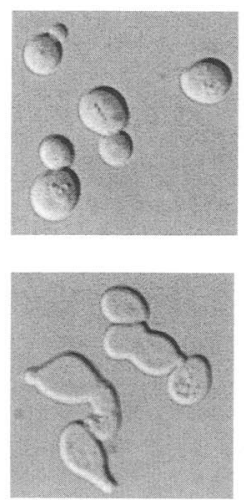

rgal bem3
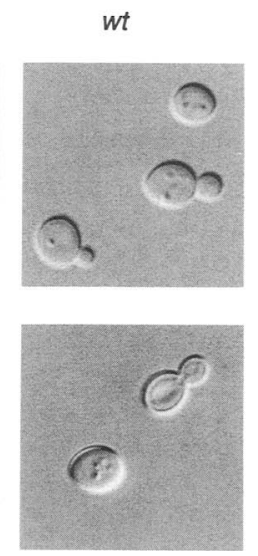

wt
Figure 7. Cell morphologies of rga1 $\Delta d c 24^{t s}$ and rga1 $\Delta$ bem $3 \Delta$ strains. Heterozygous diploids SY3043 (cdc24ts/CDC24 rga1A::URA3/RGA1) and SY3032 (bem $3 \Delta:: L E U 2 / B E M 3$ rga1 $\triangle:: U R A 3 / R G A 1$ ) were sporulated and dissected. Cells from a representative tetratype tetrad from each diploid are shown. For each diploid, at least five segregants of each genotype were examined and found to exhibit the phenotype typified by the photographs. Cells were grown at $30^{\circ} \mathrm{C}$ in YEPD medium and prepared and photographed as described in Materials and methods. under certain conditions, transfer of signal is possible between the osmotic-stress pathway and the pheromone-transduction pathway.

\section{Discussion}

We have identified a new regulator of the yeast pheromone-response pathway by identifying mutations that activate the pathway in ste $4 \Delta$ strains, which lack the $\beta$ subunit of the $\mathrm{G}$ protein. Wild-type cells that have not been stimulated with pheromone exhibit a basal signal in the pheromone pathway, presumably because such cells contain some free G $\beta \gamma$ subunit; ste $4 \Delta$ mutants lack this basal signal. Recessive mutations in RGA1, which encodes the newly identified regulator, create a signal in ste $4 \Delta$ mutants and increase the basal signal in wild-type cells. Conversely, overexpression of RGA1 reduces the basal signal in wild-type cells and dampens response to pheromone. Thus, we conclude that RGA1 encodes a negative regulator of the pheromone signal-transduction pathway. The Rgalp protein sequence shows striking sequence similarity to GTPase-activating proteins (GAPs) that promote GTP hydrolysis by $\mathrm{p} 21 \mathrm{GTP}$ ases of the Rho subfamily. It seems likely, therefore, that Rgalp functions to modulate the pheromone-response pathway by

Table 4. FUS1-lacZ expression in $\mathrm{pbs} 2 \Delta$ strains subjected to osmotic stress

\begin{tabular}{|c|c|c|}
\hline \multirow[b]{2}{*}{ Strain } & \multicolumn{2}{|c|}{ FUS1-lacZ activity ${ }^{a}$} \\
\hline & - sorbitol & + sorbitol $^{b}$ \\
\hline ste $4 \Delta p b s 2 \Delta$ & 0.23 & 2.2 \\
\hline ste $5 \Delta p b s 2 \Delta$ & 0.21 & 2.3 \\
\hline ste20 $20 b s 2 \Delta$ & 0.4 & 0.9 \\
\hline ste $11 \Delta p b s 2 \Delta$ & 0.2 & 0.2 \\
\hline
\end{tabular}

${ }^{\text {a }}$ alues are averages of four determinations (two each in MATa and MAT $\alpha$ strains).

${ }^{\mathrm{b}} \mathrm{Cells}$ were grown in $0.4 \mathrm{M}$ sorbitol for $1 \mathrm{hr}$ at $30^{\circ} \mathrm{C}$. regulating a $\mathrm{Rho} / \mathrm{Rac}$ GTPase, which itself functions as a positive regulator of the pathway.

Genetic and two-hybrid experiments indicate that Cdc42p, a Rho/Rac GTPase required for polarity establishment during budding, is an important target of Rgalp, and we suggest that Cdc42p is also a positive regulator of the pheromone-response pathway. Support for this suggestion comes from biochemical studies with mammalian cells and genetic and biochemical studies with yeast. Manser et al. (1994) showed that the GTPbound form of mammalian Cdc $42 p$ could bind to a Ste20p homolog, $\mathrm{p} 65^{\mathrm{PAK}}$, stimulating it to autophosphorylate and thereby become an active protein kinase capable of phosphorylating other substrates. Consistent with these observations, Simon et al. (1995) and Zhao et al. (1995) found that yeast Cdc42p and Ste20p interact both in the two-hybrid system and in vitro. Moreover, these authors found that $c d c 42$ and $c d c 24$ temperaturesensitive mutants failed to respond to pheromone at the restrictive temperature as measured by induction of a FUS1-lacZ reporter and were released from cell-cycle arrest when cells arrested by pheromone at permissive temperature were shifted to restrictive temperatures. Taken together, these data suggest that Rgalp acts as a GAP for Cdc42p, which in turn affects signaling in the pheromone-response pathway through the Ste20p protein kinase.

Two observations complicate the relatively simple picture presented above. First, deletion of STE20 reduces, but does not abolish, pathway activation caused by mutation of RGA1. Perhaps GTP-bound Cdc42p can activate other protein kinases that can substitute, at least partially, for Ste20p. For example, Cdc42p also interacts with Cla4p, a protein that is homologous to Ste20p (Cvrcková et al. 1995). These two protein kinases are partially redundant in function during vegetative growth: the double mutant is inviable, whereas either single mutant is viable (Cvrcková et al. 1995). Perhaps there is also some redundancy during pheromone signaling. Another possibility is that GTP-bound Cdc42p may directly activate Stellp. The second complication is that mutations that should trap Cdc42p in the GTP-bound state le.g., 
Cdc42p $\mathrm{p}^{\mathrm{G} 12 \mathrm{~V}}$ ) do not by themselves cause constitutive activation of the pheromone pathway, although they do make cells more sensitive to pheromone (Simon et al. 1995). Perhaps Cdc42p must hydrolyze the bound GTP to achieve stimulation of the pheromone pathway. Perhaps Rgalp is itself a target of one of the early components of the pheromone pathway and, unless it has received a signal from that component, prevents Cdc42p from activating Ste20p. Or, perhaps an as-yet-unidentified GTPase is the relevant target of Rgalp with respect to the pheromone pathway signal generated in rgal mutants.

The postulated role of $\mathrm{Cdc} 42 \mathrm{p}$ in pheromone signal transmission raises the possibility that it may be an integral part of a switch that controls cellular morphology: Vegetative cells form buds at discrete and predictable sites, whereas pheromone-stimulated cells cease budding and form mating projections oriented toward the pheromone source. Cdc42p is thought to participate in bud-site selection and bud initiation by interaction with other proteins in a morphogenetic hierarchy that includes proteins (such as Rsrlp) dedicated to bud-site selection, as well as other proteins (such as Cdc24p) that are essential for polarity establishment (Bender and Pringle 1989; Park et al. 1993; Zheng et al. 1994, 1995; Pringle et al. 1995). The constellation of proteins with which $\mathrm{Cdc} 24 \mathrm{p}$ and $\mathrm{Cdc} 42 \mathrm{p}$ interact may change upon pheromone stimulation. For example, they may interact, directly or indirectly, with the membrane-bound $G \beta \gamma$ dimer. Such new interactions may recruit Cdc24p and Cdc42p away from the predetermined site for bud emergence and to a site appropriate for projection formation. Similarly, the new interactions may facilitate interaction with, and stimulation of, Ste20p. A dual role for p21 GTPases is not unprecedented. In the fission yeast Schizosaccharomyces pombe, Raslp is argued to participate both in mating and in morphogenesis (Chang et al. 1994).

The possibility that Cdc42p has dual (or multiple) roles, or at least is subject to two or more regulatory inputs, is also suggested by the existence of two GAPs for this protein. Outside the GAP domains, Bem $3 p$ and Rgalp show no sequence similarity. For example, Rgalp contains two LIM domains, which are thought to be zinc-binding domains that mediate protein-protein interaction, whereas Bem3p lacks LIM domains. Thus, Rgalp and Bem3p likely interact with different proteins and may, therefore, provide a way for distinct signals to influence the activity of Cdc42p. Moreover, it is possible that there are additional GAPs for Cdc42p. A cell lacking either Cdc42p or Cdc24p activity is inviable, whereas a cell lacking both Rgalp and Bem3p is viable, although noticeably misshapen. Cdc $42 p$ may have sufficient inherent, unstimulated GTPase activity to maintain viability (Zheng et al. 1994). On the other hand, perhaps an additional protein(s) with GAP activity towards Cdc42p remains to be discovered. Understanding the regulatory inputs that influence Cdc42p activity, and the spectrum of physiological processes that Cdc $42 p$ in turn governs, are important challenges for the future.

\section{Materials and methods}

Strains, plasmids, and microbiological techniques

The yeast strains used in this work are listed in Table 5. The pheromone responsive FUS1::HIS3 construct and plasmids used to introduce deletions at the chromosomal STE loci have been described previously (Stevenson et al. 1992). STE20 was deleted by use of pEL45 (ste20A::URA3; Leberer et al. 1992). For the deletion of PBS2, the SacI fragment of pJB40, containing pbs2 2 ::URA3 (Brewster et al. 1993), was subcloned into the nonreplicating vector pRS306 (Sikorski and Hieter 1989), and the resultant plasmid was digested with SacI before transformation. A deletion allele of RGA1 (rga1 $:: L E U 2)$ was created by subcloning of the 5.8-kb HindIII fragment into pIC19H (Marsh et al. 1984) and replacement of the largest SpeI-Eco47III fragment with an NheI-SmaI fragment containing the LEU2 gene from YDpL (Berben et al. 1991). This deletion removes all of the RGA1 ORF. An rga1::URA3 allele was constructed by replacing the larger Xhol-BamHI fragment with the $U R A 3$ gene carried on a Sall-SmaI fragment from YDpU (Berben et al. 1991). This allele deletes the amino-terminal third of the RGA1 open reading frame and gives rise to a phenotype indistinguishable from rga1::LEU2. Constructs used for segregation analysis were produced by subcloning of fragments from the cloned genomic DNAs into modified versions of the integrating vector pRS306 (Sikorski and Hieter 1989); a 5.8-kb HindIII fragment was subcloned from pRGA1.3 to give pRGAl.INT, and a 6.1-kb PstI fragment was subcloned from pPBS2.16 to give pPBS2.INT. Chromosomal deletions of genes were produced by one-step gene replacement (Rothstein 1991) and were verified by Southern analysis (Southern 1975). The pGAL-RGA1 expression plasmid was constructed by introducing SacI restriction sites $5^{\prime}$ of the presumed initiation codon and $3^{\prime}$ of the stop codon through PCR amplification. The resulting fragment was ligated into pSL1597 (constructed by C. Boone, Simon Fraser University, Burnaby, British Columbia, Canada), a pRS316-based plasmid (Sikorski and Hieter 1989) containing a 0.8-kb fragment of the GAL1 promoter. The multicopy plasmid YEp13-RGA1 was constructed by ligation of the 5.8 -kb HindIII fragment including $R G A 1$ into YEpl3 (Broach et al. 1979). YEp13-BEM3 was a gift from A. Bender (Indiana University, Bloomington).

Yeast and bacterial strains were propagated by use of standard methods. YEPD and SD media were prepared as described (Rose et al. 1990). Yeast transformations were performed by use of a modification of the $\mathrm{Li}^{+}$ion method (Gietz et al. 1992). Bacterial transformations, DNA preparations, and plasmid constructions were performed by standard methods (Sambrook et al. 1989).

\section{Two-hybrid assays}

Two different two-hybrid systems were used in the analysis of Rgalp. In the study of interactions with Ste proteins, a lexA$R G A 1$ gene fusion was constructed by the polymerase chain reaction (PCR) addition of EcoRI restriction sites immediately 3 ' of the $R G A 1$ initiation codon (creating a deletion of the first three amino acids and an addition of two amino acids, EF) and $3^{\prime}$ of the stop codon. The resulting fragment was ligated into plasmid pMA424 (Ma and Ptashne 1987). The Gal4 activation domain fusions containing Ste $4 p, S t e 5 p, S t e 11 p, S t e 7 p$, and Fus $3 p$ were previously described (Printen and Sprague 1994). Interactions were assayed in strain CTY10-5D (gift of S. Fields).

In the Cdc42p experiments, the two-hybrid system of Gyuris et al. (1993) was used. To construct fusions of various GTPase proteins to the LexA DNA-binding domain (DBD) in pEG202, $S$. cerevisiae CDC42 (Johnson and Pringle 1990), CDC42 ${ }^{C 188 S}$ ( $\mathrm{Zi}$ man et al. 1991), RHO1 and RHO2 (Madaule et al. 1987), RHO3 
Table 5. Yeast strains

\begin{tabular}{|c|c|c|}
\hline Strain & Genotype & Source \\
\hline 227 & MATa lys 1 cry1 & $\begin{array}{l}\text { I. Herskowitz } \\
\text { (University of } \\
\text { California, } \\
\text { San Francisco) }\end{array}$ \\
\hline YEF24H & MAT $\alpha$ cdc24- $H^{t s}$ ura3 trp1 leu2 his4 ade2 & J. Pringle \\
\hline DJTD2-16D & MAT $\alpha c d c 42-1^{t s}$ ura3 trp1 leu2 his4 gal2 & $\begin{array}{l}\text { Johnson et al. } \\
\text { (1987) }\end{array}$ \\
\hline ABY 646 & MATa bem3::LEU2 ura3 leu2 & $\begin{array}{l}\text { A. Bender } \\
\text { (Indiana } \\
\text { University, } \\
\text { Bloomington) }\end{array}$ \\
\hline CTY10-5D & MATa ade2 trp1-901 leu2-3,112 his3-200 gal4 gal80 URA3::lacZop-lacZ & $\begin{array}{l}\text { S. Fields } \\
\text { (University of } \\
\text { Washington, } \\
\text { Seattle) }\end{array}$ \\
\hline EGY48 & MAT $\alpha$ his3 trp1 ura3-52 lexA-LEU2 & $\begin{array}{l}\text { Gyuris et al. } \\
\text { (1993) }\end{array}$ \\
\hline SY1731 (27) & 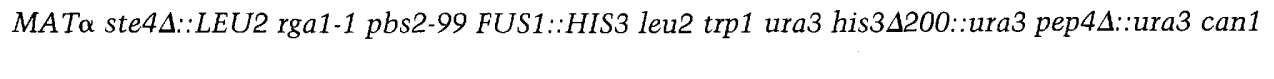 & $\begin{array}{l}\text { Stevenson et al. } \\
\text { (1992) }\end{array}$ \\
\hline SY2002 & MATa FUS1::HIS3 his3 mfa2-A1::FUS1-lacZ ade1 leu2 trp1 ura3 & lab strain \\
\hline SY2003 & MAT $\alpha$ FUS1::HIS3 his3 mfa2-A1::FUS1-lacZ ade1 leu2 trp1 ura3 & lab strain \\
\hline SY3032 & MATa/MATa diploid from SY3064 × ABY 646 & this study \\
\hline SY3043 & $M A T \mathbf{a} / M A T \alpha$ diploid from BSY109 and YEF24H & this study \\
\hline SY3064 & SY2003 except rgal1::URA3 & this study \\
\hline SY3116 & SY2002 except rga1-1 & this study \\
\hline BSY109 & SY2002 except RGA1::URA3::RGA1 & this study \\
\hline BSY110 & SY2002 except PBS2::URA3::PBS2 & this study \\
\hline BSY106 & MAT $\alpha$ ste4A::LEU2 rga1-1 pbs2-99 FUS1::HIS3 his $3 \Delta 200$ ade1 leu2 trp1 ura3 & this study \\
\hline BSY146 & 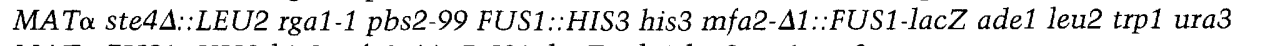 & this study \\
\hline BSY $179^{a}$ & MAT $\alpha$ FUS1::HIS3 his3 mfa2- $11:: F U S 1-1 a c Z$ ade1 leu2 trp1 ura3 & this study \\
\hline BSY183 & BSY179 except rga1-1 & this study \\
\hline BSY185 & BSY179 except rga1-1 pbs2-99 & this study \\
\hline BSY187 & BSY179 except ste $4 \Delta:: L E U 2$ & this study \\
\hline BSY191 & BSY179 except ste $4 \Delta:: L E U 2$ rga1-1 & this study \\
\hline BSY193 & BSY179 except ste $4 \Delta:: L E U 2$ rga1-1 pbs2-99 & this study \\
\hline BSY194 & MATa ste4A::LEU2 rga1-1 pbs2-99 FUS1::HIS3 his3 mfa2- $\Delta 1:: F U S 1-1 a c Z$ ade1 leu2 trp1 ura3 & this study \\
\hline BSY171 & SY2003 except ste4A::URA3 & this study \\
\hline BSY173 & SY2003 except ste5 $\Delta:: U R A 3$ & this study \\
\hline BSY160 & SY2003 except ste11 $1:: U R A 3$ & this study \\
\hline BSY217 & SY2003 except ste20A::URA3 & this study \\
\hline BSY215 & SY2003 except ste4A::URA3 pbs2 $:: U R A 3$ & this study \\
\hline BSY244 & SY2003 except ste4A::URA3 rga1A::LEU2 & this study \\
\hline BSY246 & SY2003 except ste4A::URA3 rga1 $:: L E U 2$ pbs $2 \Delta:: U R A 3$ & this study \\
\hline BSY240 & SY2003 except rga1 $1:: L E U 2$ & this study \\
\hline BSY242 & SY2003 except rga1 $::: L E U 2$ pbs2 $2:: U R A 3$ & this study \\
\hline BSY $219^{b}$ & 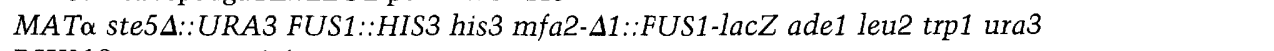 & this study \\
\hline BSY221 & BSY219 except $r g a 1-1$ & this study \\
\hline BSY223 & BSY219 except rga1-1 pbs2-99 & this study \\
\hline BSY225 & 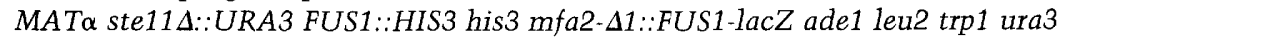 & this study \\
\hline BSY227 & BSY225 except rga1-1 & this study \\
\hline BSY229 & BSY225 except rga1-1 pbs2-99 & this study \\
\hline BSY $231^{\mathrm{d}}$ & 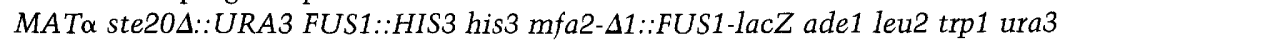 & this study \\
\hline BSY233 & BSY231 except rgal-1 & this study \\
\hline BSY235 & BSY231 except $r g a 1-1$ pbs2-99 & this study \\
\hline
\end{tabular}

${ }^{a}$ BSY179-BSY194 are isogenic segregants from a BSY146 $\times$ SY2002 cross. bBSY219-BSY223 are isogenic segregants from a BSY194 $\times$ BSY173 cross. 'BSY225-BSY193 are isogenic segregants from a BSY194 $\times$ BSY215 cross. ${ }^{d}$ BSY231-BSY235 are isogenic segregants from a BSY194 $\times$ BSY217 cross. 
and RHO4 (Matsui and Toh-e 1992; YKRO55W, accession no. Z28280, MIPS), RSR1 (Bender and Pringle 1989), RSR1G12V (Ruggieri et al. 1992), and RAS2 (Powers et al. 1984) full-length coding sequences were amplified by PCR with Vent polymerase (New England Biolabs). Plasmids containing the genes were used as templates, and appropriate restriction sites were introduced with the primers. The mutant genes $C D C 42^{G 12 V, C 188 S}$,

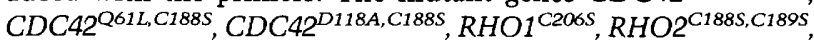
$\mathrm{RHO}^{\mathrm{C} 228 \mathrm{~S}}$, and $\mathrm{RHO} 4^{\mathrm{C} 288 S}$ were amplified by use of plasmids containing $C D C 42^{G 12 V}, C D C 42^{\mathrm{Q} 61 L}, C D C 42^{D 118 A}$ (Ziman et al. 1991), RHO1, RHO2, RHO3, and $\mathrm{RHO} 4$ as templates and reverse primers that specifically introduced the various $C-S \mathrm{mu}$ tations (bold letters) as well as a XhoI cloning site (italic letters): $C D C 42^{C 1885}$, 5'-ATATACTACTCGAGCTACAAAATTGTAGATTTTTTACTTTTCTTG-3'; RHO1 ${ }^{\text {C206S }}$, 5'-GAGATCGAGCTCGAGCTATAACAAGACAGACTTCTTCTTCTTCT3'; RHO2 $^{C 188 S, C 189 S}, 5^{\prime}$-CAGTGTAAGCTCGAGTTATAAAATTATGGAAGAGTTAGCCCCTGG- $3^{\prime} ;$ RHO $^{\mathrm{C} 228 \mathrm{~S}}, 5^{\prime}$-TATATATATACTCGAGTTACATAATGGTAGAGCTGGATCCACTG-3'; RHO4 ${ }^{\mathrm{C} 288 \mathrm{~S}}$, 5'-CTTCATCACTCGAGTTACATTATAATAGACTTGTTTTTTCTTAA-3'.

The PCR products were cloned either at the EcoRI-XhoI sites (all but RSR1) or at the BamHI-XhoI sites (RSR1) of pEG202. Accordingly, all constructs, except for that involving RSR1, contain two additional amino acids $(E F)$ between the last amino acid of the LexA DBD and the first amino acid (M) of the fused protein. LexA-Rsrlp contains five additional amino acids (EFPGI) between the LexA DBD and the first amino acid (R, corresponding to the second amino acid of Rsrlp) of the fused Rsrlp. All constructs contain the original stop codons of the fused genes.

To construct fusions of Bem3p (Bender and Pringle 1991; Zheng et al. 1994) and Rgalp to the LexA DBD in pEG202, both full-length coding sequences were amplified by PCR as described above, by use of plasmids containing either $B E M 3$ or $R G A 1$ as template. The PCR products were cloned either at the EcoRI-NcoI sites (BEM3) or at the NcoI-Xhol sites (RGA1) of pEG202. Accordingly, the Bem3p construct contains two additional amino acids $(E F)$ and the Rgalp construct nine additional amino acids (EFPGIRRPW) between the last amino acid of the LexA DBD and the first amino acid (M) of the fused protein. Both constructs contain the original stop codons of the fused genes.

For construction of fusions of the various proteins to the activation domain $(A D)$ in pJG4-5, the desired sequences were amplified by PCR as described above and cloned into pJG4- 5 by use of the EcoRI and Xhol sites $\mid C D C 42, C D C 42^{C 188 S}$, $C D C 42^{G 12 V, C 188 S}$, and CDC42 $261 L, C 188 S \mid$, the EcoRI and NcoI sites (BEM3), or the NcoI and Xhol sites (RGA1) of a pJG4-5 that had been modified to include an $\mathrm{Ncol}$ site in its polylinker.

For assessment of $\beta$-galactosidase activities, strain EGY48 containing the lexAop-lacZ reporter plasmid pSH18-34 /Gyuris et al. 1993) was cotransformed either with pEG202 or with a pEG202-derived plasmid expressing a LexA DBD fusion protein and with pJG4-5 or a pJG4-5-derived plasmid expressing an ADfusion protein. $\beta$-Galactosidase activities were measured in three to six different isolates of each strain after growth for $16 \mathrm{hr}$ at $30^{\circ} \mathrm{C}$ in minimal medium containing $2 \%$ galactose, $1 \%$ raffinose, and $0.1 \mathrm{mg} / \mathrm{ml} \mathrm{L}$-leucine. The average $\beta$-galactosidase activities (in Miller units) are reported.

\section{Genetic analysis of mutant 27}

Mutant 27 (SY1731; Stevenson et al. 1992) was isolated on the basis of its ability to activate expression of FUS1::HIS3 and to mate in the absence of a functional $G$ protein. Preliminary char- acterization of this strain revealed that, unlike the parent strain, it grew poorly on media of high osmolarity (1 M sorbitol). To determine if these phenotypes were linked, the mutant was crossed four times to SY2002. SY2002 carries FUS1::HIS3 at his3 and a FUS1-lacZ construct at mfa2d (Boone et al. 1993). Analysis of the progeny of these crosses indicated that two unlinked mutations were responsible for the phenotypes of the original mutant. One of the mutations (rga1-1) activated expression of FUS1 in a ste $4 \Delta$ background, but did not by itself restore mating ability. The second mutation (pbs2-99) conferred an osmotic sensitivity phenotype but did not activate expression of FUS1. The presence of both rga1-1 and pbs2-99, however, gave higher expression of FUS1 (than rga1-1 alone) and allowed mating in a ste $4 \Delta$ background (see Table 1).

\section{Cloning and sequencing of RGAl}

Mutant 27 (SY1731) was transformed to uracil prototrophy with a high-copy, yeast genomic library (Carlson and Botstein 1982), and colonies were replica-plated to solid medium lacking histidine to screen for plasmid-mediated reduction of expression of FUS1::HIS3. A total of five distinct plasmids that conferred the same phenotype upon retransformation into SY1731 were analyzed further by restriction enzyme analysis. Three plasmids (designated pRGA1.3, pRGA1.4, and pRGAl.17) contained overlapping inserts representing about $20 \mathrm{~kb}$ of genomic DNA. This group of plasmids complemented the FUS1 expression phenotype, but not the osmotic-sensitivity phenotype, of the original strain. The second group, comprising two plasmids with overlapping inserts (designated pPBS2.1 and pPBS2.16) complemented both phenotypes. In a separate experiment, several plasmids with inserts overlapping those of pPBS2.1 and pPBS2.16 were cloned by screening for growth of mutant 27 on media containing $1 \mathrm{M}$ sorbitol after transformation with a CENbased genomic library.

Linkage analysis was performed to verify that the cloned genes represented wild-type versions of the mutant alleles and not high-copy suppressors. SY2002 (MATa FUS1::HIS3) was transformed with either pRGAl.INT linearized with XhoI or pPBS2.INT linearized with $X b a I$. Strains with correct integration of pRGA1.INT (BSY109) or pPBS2.INT (BSY110) were

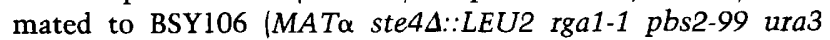
FUS1::HIS3). The diploids were sporulated and segregants assayed for the presence of the cloned gene $\left(\mathrm{Ura}^{+}\right)$, expression of FUS1::HIS3 in ste $4 \Delta$ cells (His ${ }^{+}$or His ${ }^{-}$), and growth on high osmolarity medium (1 $\mathrm{M}$ sorbitol). In 19 tetrads analyzed from the BSY $109 \times$ BSY 106 cross all except one of the 38 ste $4 \Delta$ segregants were $\mathrm{Ura}^{+} \mathrm{His}^{-}(15)$ or $\mathrm{Ura}^{+} \mathrm{His}^{+}(22)$, and about half of all Ura ${ }^{+}(20 / 37)$ and half of all Ura ${ }^{-}(18 / 39)$ segregants were able to grow well on $1 \mathrm{M}$ sorbitol. These data indicate that the cloned pRGA1 DNA is linked to the rga1-1 locus. In the BSY $110 \times$ BSY106 cross, all segregants were either $\mathrm{Ura}^{+}$and grew well on $1 \mathrm{~m}$ sorbitol $(34)$ or $\mathrm{Ura}^{-}$and sensitive to $1 \mathrm{M}$ sorbitol (34) (i.e., parental ditype), indicating that the cloned pPBS2 was indeed linked to the mutation ( $p b s 2-99$ ) which conferred the osmotic-sensitivity phenotype.

The RGA1 gene was located within pRGAl.3 by subcloning of restriction enzyme fragments of the genomic insert into pRS316 (Sikorski and Hieter 1989) and testing for complementation after transformation into SY1731. For generation of nested deletions for DNA sequencing by use of exonuclease III, the complementing 5.8-kb HindIII fragment was cloned in both directions in pRS316 and digested with SacI (exonuclease IIIresistant ends) and EcoRI (exonuclease III-sensitive ends) prior to exonuclease III treatment. Useful deletions were converted to single-stranded templates by use of $\mathrm{Ml3}$ KO7 helper phage 
(Vieira and Messing 1987) and their sequences were determined by use of the dideoxy chain-termination method (Sanger et al. 1977). The 4.1-kb ClaI-HindIII fragment was completely sequenced on both strands. The RGA1 DNA sequence has been deposited in the EMBL, GenBank and DDJB nucleotide sequence databases under accession number X90950.

\section{$\beta$-Galactosidase and mating assays}

Cells containing a FUS1-lacZ construct integrated at mfa2d were diluted from a fresh overnight culture in YEPD medium and grown for about $6 \mathrm{hr}$, to mid-log phase at $30^{\circ} \mathrm{C}$. Cells were prepared and assayed as described previously (Jarvis et al. 1988). Quantitative mating assays using 227 as a tester strain were performed by a filter mating assay as described /Clark and Sprague 1989|.

\section{Microscopy}

Cells were grown in YEPD medium to a density of $4-8 \times 10^{6}$ cells $/ \mathrm{ml}$, sonicated for $5 \mathrm{sec}$, then concentrated by centrifugation. Cell pellets were either resuspended in water or in $1 \mu \mathrm{g} / \mathrm{ml}$ Calcofluor (Sigma) for $20 \mathrm{~min}$, then washed with water and visualized on a Zeiss Axioplan photomicroscope with a $100 \times$ objective.

\section{Acknowledgments}

We thank A. Bender, D. Johnson, A. Myers, Y. Matsui, and R. Brent for providing strains and plasmids. This work has been supported by U.S. Public Health Service research grants GM30027 (awarded to G.F.S.) and GM31006 (awarded to J.R.P.) and by an Austrian Fonds zur Förderung der wissenschaftlicken Forschung grant P9339 (awarded to G.A.). B.J.S. and E.B. were supported by fellowships from the Damon Runyon-Walter Winchell Cancer Fund (DRG-977 and DRG-1197, respectively). C.D.V. was supported by fellowships from the L. and Th. La Roche Stiftung and the Ciba-Gigy-Jubilaeums-Stiftung. B.M.F. was supported by fellowships from The Burroughs-Wellcome Research Fund and the American Heart Association, Oregon Affiliate, Inc.

The publication costs of this article were defrayed in part by payment of page charges. This article must therefore be hereby marked "advertisement" in accordance with 18 USC section 1734 solely to indicate this fact.

\section{References}

Altschul, S.F., W. Gish, W. Miller, E.W. Myers, and D.J. Lipman. 1990. Basic local alignment search tool. J. Mol. Biol. 215: 403-410.

Archer, V.E.V., J. Breton, I. Sanchez-Garcia, H. Osada, A. Forster, A.J. Thomson, and T.H. Rabbitts. 1994. Cysteine-rich LIM domains of LIM-homeodomain and LIM-only proteins contain zinc but not iron. Proc. Natl. Acad. Sci. 91: 316-320.

Barfod, E.T., Y. Zheng, W.-J. Kuang, M.J. Hart, T. Evans, R.A. Cerione, and A. Ashkenazi. 1993. Cloning and expression of a human CDC42 GTPase-activating protein reveals a functional SH3-binding domain. I. Biol. Chem. 268: 2605926062.

Bender, A. and J.R. Pringle. 1989. Multicopy suppression of the cdc24 budding defect in yeast by CDC42 and three newly identified genes including the ras-related gene RSR1. Proc. Natl. Acad. Sci. 86: 9976-9980.

- 1991. Use of a screen for synthetic lethal and multicopy suppressee mutants to identify two new genes involved in morphogenesis in Saccharomyces cerevisiae. Mol. Cell. Biol. 11: 1295-1305.

Berben, G., J. Dumont, V. Gilliquet, P. Bolle, and F. Hilger. 1991. The YDp plasmids: a uniform set of vectors bearing versatile gene disruption cassettes for Saccharomyces cerevisiae. Yeast 7: 475-477.

Boguslawski, G. 1992. PBS2, a yeast gene encoding a putative protein kinase, interacts with the RAS2 pathway and affects osmotic sensitivity of Saccharomyces cerevisiae. J. Gen. Microbiol. 138: 2425-2432.

Boguslawski, G. and J.O. Polazzi. 1987. Complete nucleotide sequence of a gene conferring polymyxin $B$ resistance on yeast: Similarity of the predicted polypeptide to protein kinases. Proc. Natl. Acad. Sci. 84: 5848-5852.

Boone, C., N.G. Davis, and G.F. Sprague, Jr. 1993. Mutations that alter the third cytoplasmic loop of the a-factor receptor lead to a constitutive and hypersensitive phenotype. Proc Natl. Acad. Sci. 90: 9921-9925.

Brewster, J.L., T. de Valoir, N.D. Dwyer, E. Winter, and M.C. Gustin. 1993. An osmosensing signal transduction pathway in yeast. Science 259: 1760-1763.

Broach, J.R., J.N. Strathern, and J.B. Hicks. 1979. Transformation in yeast: Development of a hybrid cloning vector and isolation of the CAN1 gene. Gene 8: 121-133.

Cairns, B.R., S.W. Ramer, and R.D. Kornberg. 1992. Order of action of components in the yeast pheromone response pathway revealed with a dominant allele of the STE 11 kinase and multiple phosphorylation of the STE7 kinase. Genes \& Dev. 6: 1305-1318.

Carlson, M. and D. Botstein. 1982. Two differentially regulated mRNAs with different 5 ' ends encode secreted and intracellular forms of yeast invertase. Cell 28: 145-154.

Chang, E.C., M. Barr, Y. Wang, V. Jung H.-P. Xu, and M.H. Wigler. 1994. Cooperative interaction of $S$. pombe proteins required for mating and morphogenesis. Cell 79: 131-141.

Chang, F. and I. Herskowitz. 1991. Identification of a gene necessary for cell cycle arrest by a negative growth factor of yeast: FAR1 is an inhibitor of a G1 cyclin, CLN2. Cell 63: 999-1011.

Chant, J. and I. Herskowitz. 1991. Genetic control of bud site selection in yeast by a set of gene products that constitute a morphogenetic pathway. Cell 65: 1203-1212.

Chant, J., and J. R. Pringle. 1995. Patterns of bud-site selection in the yeast Saccharomyces cerevisiae. I. Cell Biol. 129:751765.

Choi, K.Y., B. Satterberg, D.M. Lyons, and E.A. Elion. 1994. Ste5 tethers multiple protein kinases in the MAP kinase cascade required for mating in S. cerevisiae. Cell 78: 499-512.

Clark, K.L. and G.F. Sprague Jr. 1989. Yeast pheromone response pathway: Characterization of a suppressor that restores mating to receptorless mutants. Mol. Cell. Biol. 9: 2682-2694.

Crawford, A.W., J.D. Pino, and M.C. Beckerle. 1994. Biochemical and molecular characterization of the chicken cysteinerich protein, a developmentally regulated LIM-domain protein that is associated with the actin cytoskeleton. $J$. Cell Biol. 124: 117-127.

Cvrcková, F., C.D. Virgilio, E. Manser, J.R. Pringle, and K. Nasmyth. 1995. Ste20-like protein kinases are required for normal localization of cell growth and for cytokinesis in budding yeast. Genes \& Dev. 9: 1817-1830.

Devereux, J., P. Haeberli, and O. Smithies. 1984. A comprehensive set of sequence analysis programs for the VAX. Nucleic Acid Res. 12: 387-395.

Dolan, J.W. and S. Fields. 1989. The yeast STE12 protein binds to the DNA sequence mediating pheromone induction. Proc. 
Natl. Acad. Sci. 86: 5703-5707.

Elion, E.A., B. Satterberg, and J.E. Kranz. 1993. FUS3 phosphorylates multiple components of the mating signal transduction cascade: Evidence for STE12 and FAR1. Mol. Biol. Cell 4: $495-510$.

Errede, B. and G. Ammerer. 1989. STE12, a protein involved in cell-type-specific transcription and signal transduction in yeast, is part of protein-DNA complexes. Genes \& Dev. 3: 1349-1361.

Errede, B., A. Gartner, Z.-Q. Zhou, K. Nasmyth, and G. Ammerer. 1993. MAP kinase-related FUS3 from $S$. cerevisiae is activated by STE7 in vitro. Nature 362: 261-264.

Fields, S. and O. Song. 1989. A novel genetic system to detect protein-protein interactions. Nature 340: 245-246.

Freyd, G., S.K. Kim, and H.R. Horvitz. 1990. Novel cysteine-rich motif and homeodomain in the product of the Caenorhabditis elegans cell lineage gene lin-11. Nature 344: 876-879.

Gartner, A., K. Nasmyth, and G. Ammerer. 1992. Signal transduction in $S$. cerevisiae requires tyrosine and threonine phosphorylation of FUS3 and KSS1. Genes \& Dev. 6: 12801292.

Gietz, D., A. St. Jean, R.A. Woods, and R.H. Schiestl. 1992. Improved method for high efficiency transformation of intact yeast cells. Nucleic Acids Res. 20: 1425.

Gyuris, J., E. Golemis, H. Chertkov, and R. Brent. 1993. Cdi1, a human $\mathrm{Gl}$ and $\mathrm{S}$ phase protein phosphatase that associates with Cdk2. Cell 75: 791-803.

Hagen D.C., G. McCaffrey, and G.F. Sprague, Jr. 1991. Pheromone response elements are necessary and sufficient for basal and pheromone-induced transcription of the FUS1 gene of Saccharomyces cerevisiae. Mol. Cell. Biol. 11: 29522961.

Hall, C., C. Monfries, P. Smith, H.H. Lim, R. Kozma, S. Ahmed, V. Vanniasingham, T. Leung, and L. Lim. 1990. Novel human brain cDNA encoding a $34,000 M_{\mathrm{r}}$ protein n-chimaerin, related to both the regulatory domain of protein kinase $C$ and $\mathrm{BCR}$, the product of the breakpoint cluster region gene. J. Mol. Biol. 211: 11-16.

Heisterkamp, N., K. Stam, J. Groffen, A. de Klein, and G. Grosveld. 1985. Structural organization of the bcr gene and its role in the $\mathrm{Ph}^{\prime}$ translocation. Nature 315: 758-761.

Jarvis, E.E., D.C. Hagen, and G.F. Sprague Jr. 1988. Identification of a DNA segment that is necessary and sufficient for $\alpha$-specific gene control in Saccharomyces cerevisiae: implications for regulation of $\alpha$-specific and a-specific genes. Mol. Cell. Biol. 8: 309-320.

Johnson, D.I. and J.R. Pringle. 1990. Molecular characterization of CDC42, a Saccharomyces cerevisiae gene involved in the development of cell polarity. J. Cell Biol. 111: 143-152.

Johnson, D.I., C.W. Jacobs, J.R. Pringle, L.C. Robinson, G.F. Carle, and M.V. Olson. 1987. Mapping of the Saccharomyces cerevisiae $C D C 3, C D C 25$, and $C D C 42$ genes to chromosome XII by chromosome blotting and tetrad analysis. Yeast 3: 243-253.

Karlsson, O., S. Thor, T. Norbet, H. Ohlsson, and T. Edlund. 1990. Insulin gene enhancer binding protein Isl-1 is a member of a novel class of proteins containing both a homeo- and a Cys-His domain. Nature 344: 879-882.

Kranz, J.E., B. Satterberg, and E.A. Elion. 1994. The MAP kinase Fus 3 associates with and phosphorylates the upstream signaling component Ste5. Genes \& Dev. 8: 313-327.

Kurjan, J. 1993. The pheromone response pathway in Saccharomyces cerevisiae. Annu. Rev. Genet. 27: 147-179.

Lancaster, C.A., P.M. Taylor-Harris, A.J. Self, S. Brill, H.E. van Erp, and A. Hall. 1994. Characterization of rho GAP. J. Biol. Chem. 269: 1137-1142.
Leberer, E., D. Dignard, D. Harcus, D.Y. Thomas, and M. Whiteway. 1992. The protein kinase homologue Ste20p is required to link the yeast pheromone response G-protein $\beta \gamma$ subunits to downstream signaling components. EMBO J. 11: 48154824.

Ma, J. and M. Ptashne. 1987. A new class of yeast transcriptional activators. Cell 51: 113-119.

Madaule, P., R. Axel, and A.M. Myers. 1987. Characterization of two members of the rho gene family from the yeast Saccharomyces cerevisiae. Proc. Natl. Acad. Sci. 84: 779-783.

Manser, E., T. Leung, H. Salihuddin, Z-S. Zhao, and L. Lim. 1994. A serine/threonine protein kinase activated by $\mathrm{Cdc} 42$ and Rac1. Nature 367: 40-46.

Marcus, S., A. Polverino, M. Barr, and M. Wigler. 1994. Complexes between STE5 and components of the pheromoneresponsive mitogen-activated protein kinase module. Proc. Natl. Acad. Sci. 91: 7762-7766.

Marsh, J.L., M. Erfle, and E.J. Wykes. 1984. The pIC plasmid and phage vectors with versatile cloning sites for recombinant selection by insertional inactivation. Gene 32: 481-485.

Marsh, L., A.M. Neiman, and I. Herskowitz. 1991. Signal transduction during pheromone response in yeast. Annu. Rev. Cell Biol. 7: 699-728.

Matsui, Y. and A. Toh-e. 1992. Yeast RHO3 and RHO4 ras superfamily genes are necessary for bud growth, and their defect is suppressed by a high dose of bud formation genes CDC42 and BEM1. Mol. Cell. Biol. 12: 5690-5699.

Michelsen, J.W., K.L. Schmeichel, M.C. Beckerle, and D.R. Winge. 1993. The LIM motif defines a specific zinc-binding protein domain. Proc. Natl. Acad. Sci. 90: 4404-4408.

Müller, L., G. Xu, R. Wells, C.P. Hollenberg, and W. Piepersberg. 1994. LRG1 is expressed during sporulation in Saccharomyces cerevisiae and contains motifs similar to LIM and rho/ racGAP domains. Nucleic Acids Res. 22: 3151-3154.

Neiman, A.M. and I. Herskowitz. 1994. Reconstitution of a yeast protein kinase cascade in vitro: Activation of the yeast MEK homologue STE7 by STE11. Proc. Natl. Acad. Sci. 91: 3398-3402.

Park, H.-O., J. Chant, and I. Herskowitz. 1993. BUD2 encodes a GTPase-activating protein for Budl/Rsrl necessary for proper bud-site selection in yeast. Nature 365: 269-274.

Peter, M., A. Gartner, J. Horecka, G. Ammerer, and I. Herskowitz. 1993. FARl links the signal transduction pathway to the cell cycle machinery in yeast. Cell 73: 747-760.

Peterson, J., Y. Zheng, L. Bender, A. Myers, R. Cerione, and A. Bender. 1994. Interactions between the bud emergence proteins Bem $1 \mathrm{p}$ and Bem $2 \mathrm{p}$ and Rho-type GTPases in yeast. $J$. Cell Biol. 127: 1395-1406.

Powers, S., T. Kataoka, O. Fasano, M. Goldfarb, J. Strathern, J. Broach, and M. Wigler. 1984. Genes in S. cerevisiae encoding proteins with domains homologous to the mammalian ras proteins. Cell 36: 607-612.

Pringle, J.R., E. Bi, H.A. Harkins, J.E. Zahner, C. De Virgilio, J. Chant, K. Corrado, and H. Fares. 1995. Establishment of cell polarity in yeast. Cold Spring Harbor Symp. Quant. Biol. 60:(in press).

Printen, J.A. and G.F. Sprague, Jr. 1994. Protein-protein interactions in the yeast pheromone response pathway: Ste $5 p$ interacts with all members of the MAP kinase cascade. Genetics 138: 609-619.

Ramer, S.W. and R.W. Davis. 1993. A dominant truncation allele identifies a gene, STE20, that encodes a putative protein kinase necessary for mating in Saccharomyces cerevisiae. Proc. Natl. Acad. Sci. 90: 452-456.

Ramer, S.W., S.J. Elledge, and R.W. Davis. 1992. Dominant genetics using a yeast genomic library under the control of a 
strong inducible promoter. Proc. Natl. Acad. Sci. 89: 1158911593.

Riles, L., J.E. Dutchik, A. Baktha, B.K. McCauley, E.C. Thayer, M.P. Leckie, V.V. Braden, J.E. Depke, and M.V. Olson. 1993. Physical maps of the six smallest chromosomes of Saccharomyces cerevisiae at a resolution of 2.6 kilobase pairs. $\mathrm{Ge}$ netics 134: 81-150.

Rose, M.D., F. Winston, and P. Hieter. 1990. Methods in yeast genetics. Cold Spring Harbor Laboratory Press, Cold Spring Harbor, N.Y.

Rothstein, R. 1991. Targeting, disruption, rescue and allele rescue: Integrative DNA transformation in yeast. Methods Enzymol. 194: 281-301.

Ruggieri, R., A. Bender, Y. Matsui, S. Powers, Y. Takai, J.R. Pringle, and K. Matsumoto. 1992. RSR1, a ras-like gene homologous to Krev-1 (smg21A/rap1A): Role in the development of cell polarity and interactions with the Ras pathway in Saccharomyces cerevisiae. Mol. Cell. Biol. 12: 758-766.

Sambrook, J., E.F. Fritsch, and T. Maniatis. 1989. Molecular cloning: A laboratory manual Cold Spring Harbor Laboratory Press, Cold Spring Harbor, N.Y.

Sanger, F., S. Nicklen, and A.R. Coulson. 1977. DNA sequencing with chain-terminating inhibitors. Proc. Natl. Acad. Sci. 74: 5463-5467.

Sikorski, R.S. and P. Hieter. 1989. A system of shuttle vectors and yeast host strains designed for efficient manipulation of DNA in Saccharomyces cerevisiae. Genetics 122: 19-27.

Simon, M.-N., C. De Virgilio, B. Souza, J.R. Pringle, A. Abo, and S.I. Reed. 1995. Role for the Rho-family GTPase Cdc42 in yeast mating pheromone signal pathway. Nature 376: 702705.

Southern, E.M. 1975. Detection of specific sequences among DNA fragments separated by gel electrophoresis. I. Mol. Biol. 98: 503-517.

Sprague Jr., G.F. and J.W. Thorner. 1992. Pheromone response and signal transduction during the mating process of Saccharomyces cerevisiae, in The molecular and cellular biology of the yeast Saccharomyces: Gene expression, (ed. E.W. Jones, J.R. Pringle, and J.R. Broach), pp. 657-744. Cold Spring Harbor Laboratory Press, Cold Spring Harbor, N.Y.

Stevenson, B.J., N. Rhodes, B. Errede, and G.F. Sprague, Jr. 1992. Constitutive mutants of the protein kinase STE11 activate the yeast pheromone response pathway in the absence of the G protein. Genes \& Dev. 6: 1293-1304.

Tanaka, K., M. Nakafuku, T. Satoh, M.S. Marshall, J.B. Gibbs, K. Matsumoto, Y. Kaziro, and A. Toh-e. 1990. S. cerevisiae genes IRA1 and IRA2 encode proteins that may be functionally equivalent to mammalian ras GTPase activating protein. Cell 60: 803-807.

Tyers M. and B. Futcher. 1993. Far1 and Fus3 link the mating pheromone signal transduction pathway to three G1-phase Cdc28 kinase complexes. Mol. Cell. Biol. 13: 5659-5669.

Vieira, J. and J. Messing. 1987. Production of single-stranded plasmid DNA. Methods Enzymol. 153: 3-11.

Way, J.C. and M. Chalfie. 1988. mec-3, a homeobox containing gene that specifies differentiation of the touch receptor neurons in C. elegans. Cell 54: 5-16.

Yashar, B., K. Irie, J. Printen, B. Stevenson, G.F. Sprague Jr., K. Matsumoto, and B. Errede. 1995. Yeast MEK-dependent signal transduction: Response thresholds and parameters af fecting fidelity. Mol. Cell. Biol. 15: (in press).

Zhao, Z.-S., T. Leung, E. Manser, and L. Lim. 1995. Pheromone signalling in Saccharomyces cerevisiae requires the small GTP-binding protein Cdc42p and its activator CDC24. Mol. Cell. Biol. 15: 5246-5257.

Zheng, Y., M.J. Hart, K. Shinjo, T. Evans, A. Bender, and R.A.
Cerione. 1993. Biochemical comparisons of the Saccharomyces cerevisiae Bem 2 and Bem 3 proteins. J. Biol. Chem. 268: 24629-24634.

Zheng, Y., R. Cerione, and A. Bender. 1994. Control of the yeast bud-site assembly GTPase Cdc42. J. Biol. Chem. 269: 23692372.

Zhou, Z.-Q., A. Gartner, R. Cade, G. Ammerer, and B. Errede. 1993. Pheromone-induced signal transduction in Saccharomyces cerevisiae requires the sequential action of three protein kinases. Mol. Cell. Biol. 13: 2069-2080.

Ziman, M., J.M. O'Brien, L.A. Ouellette, W.R. Church, and D.I. Johnson. 1991. Mutational analysis of Cdc42Sc, a Saccharomyces cerevisiae gene that encodes a putative GTP-binding protein involved in the control of cell polarity. Mol. Cell. Biol. 11: 3537-3544. 


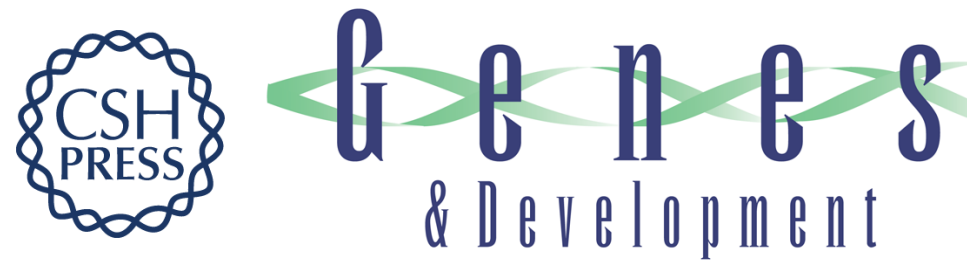

\section{Mutation of RGA1, which encodes a putative GTPase-activating protein for the polarity-establishment protein Cdc42p, activates the pheromone-response pathway in the yeast Saccharomyces cerevisiae.}

B J Stevenson, B Ferguson, C De Virgilio, et al.

Genes Dev. 1995, 9:

Access the most recent version at doi:10.1101/gad.9.23.2949

References This article cites 75 articles, 41 of which can be accessed free at: http://genesdev.cshlp.org/content/9/23/2949.full.html\#ref-list-1

License

Email Alerting

Receive free email alerts when new articles cite this article - sign up in the box at the top Service right corner of the article or click here.

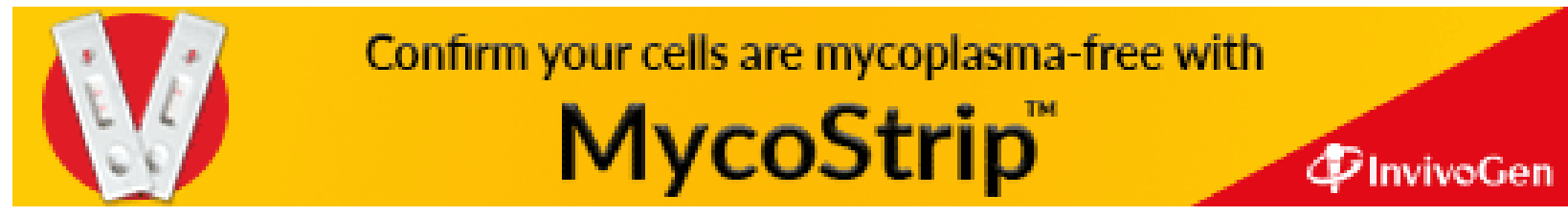

